\title{
Effect of Monoethanolamine on the Deposition Rate of Nickel in Alkaline Electroless Nickel Tartrate Baths*
}

\author{
Masao MATSUOKA** and Tadao HAYASHI**
}

\begin{abstract}
In an alkaline electroless nickel bath, changes in the concentration of monoethanolamine, and tartrate and hydrox; 1 ions were found to affect important bath parameters such as the deposition rate of nickel and stability of the bath in a characteristic manner. The deposition rate of nickel was very small in a caustic alkaline nickel tartrate bath, but increased remarkably with an addition of monoethanolamine. On the other hand, the deposition rate of nickel decreased with increasing concentration of sodium tartrate or sodium hydroxide. It was found that changes in the deposition rate of nickel with the composition of the bath were fully explained on the basis of the mixed potential theory by using the partial anodic and/or cathodic polarization curves. Spectroscopic studies in the visible region and measurements of the current-potential curves of various nickel complex solutions seemed to indicate that the increase in the deposition rate of nickel was attributable to the mixed complexes formed by nickel ion with both monoethanolamine and tartrate ion.
\end{abstract}

\section{Introduction}

In general, electroless nickel plating baths consist of (a) nickel ions, (b) suitable complexing agents, and (c) a reducing agent. It has been found that the complexing agents used in electroless nickel plating processes have a considerable effect on the deposition rate of nickel ${ }^{1 \sim^{3}}$. The role of the complexing agents in determining important bath parameters such as stability of the bath and the deposition rate of nickel has not been fully investigated. The effect of complexing agents in a mixed ligand system on the bath parameters has been discussed in the previous papers ${ }^{4), 5}$. In this study, sodium tartrate $\left(\mathrm{Na}_{2} \mathrm{~T}\right)$ and monoethanolamine (MEA) are used as complexing agents in order to attempt an improvement of electroless nickel baths. Effects of the ligands and the other components in the bath on the deposition rate of nickel were analyzed on the basis of the mixed potential theory.

\section{Experimental}

\subsection{Preparation of the bath}

All chemicals used in preparing plating

* Studies on the Electroless Nickel Plating with $\mathrm{NaBH}_{4}$ as a Reducing Agent (Part 6)

** Department of Applied Chemistry, University of Osaka Prefecture (Mozu-Umemachi, Sakai, Osaka) solutions except for monoethanolamine and nickel chloride were of special grade and were used without further purification. Nickel chloride was purified as described in the previous paper $^{6)}$, and reagent grade monoethanolamine was used without further purification.

\subsection{Deposition rate}

The electroless nickel plating solution was placed in a $250 \mathrm{ml}$ glass vessel, which was maintained at $60^{\circ} \mathrm{C}$ in a water thermostat. The deposition rate of nickel was determined gravimetrically by immersing specimens of copper sheet (about $20 \mathrm{~cm}^{2}$ surface area) in the plating solution for $20 \mathrm{~min}$ and weighing it before and after the plating. The copper sheet was treated by electrocleaning followed by the activation in the palladium chloride solution before use. No agitation was provided throughout the electroless nickel plating process. In some experiments, the amount of hydrogen gas evolved was measured in a gas-buret in the course of the plating.

\subsection{Absorption spectra}

Spectrophotometric measurements were carried out with a HITACHI spectrophotometer, model EPS-3 T, by using $1-\mathrm{cm}$ quartz cells. All of the spectrophotometric measurements were performed over the wave length of $340 \sim 700 \mathrm{~nm}$. 


\subsection{Current-potential curves}

A double jacket cell of the $\mathrm{H}$-type was used to maintain the cell temperature at $60^{\circ} \mathrm{C}$ by circulating thermostated water. Dissolved oxygen was removed by bubbling pure nitrogen gas. The potential sweep method was employed by using a potentiostat (Hokuto Denko, Type PS $500 \mathrm{~B})$ in connection with a wave form generator (Nichia Keiki, Type S-5A) for the measurements of cathodic or anodic polarization curves. Potential sweep was run at $25 \mathrm{mV} / \mathrm{s}$ unless otherwise stated and the potential of the electrode was measured with reference to an $\mathrm{Hg} / \mathrm{HgO}$ electrode. Current-potential curves were recorded on an X-Y recorder (Yokogawa, Type 3077). The counter electrode which was made of a platinum plate, has an area of about ten times larger than that of the test electrode. The test electrode was prepared by sealing a platinum wire $\left(0.1 \mathrm{~cm}^{2}\right)$ in a glass tube, on which nickel was electroplated from watts bath before use.

\subsection{Deposition rate}

\section{Results and Discussion}

The following reactions have been proposed to account for the electroless deposition of nickel in the Nibodur process ${ }^{7}$.

$$
\begin{aligned}
& \mathrm{BH}_{4}{ }^{-}+4 \mathrm{Ni}^{2+}+8 \mathrm{OH}^{-}=4 \mathrm{Ni}+\mathrm{BO}_{2}{ }^{-}+6 \mathrm{H}_{2} \mathrm{O} \\
& 2 \mathrm{BH}_{4}{ }^{-}+4 \mathrm{Ni}^{2+}+6 \mathrm{OH}^{-}=2 \mathrm{Ni}_{2} \mathrm{~B}+6 \mathrm{H}_{2} \mathrm{O}+\mathrm{H}_{2} \\
& \mathrm{BH}_{4}{ }^{-}+2 \mathrm{H}_{2} \mathrm{O}=\mathrm{BO}_{2}{ }^{-}+4 \mathrm{H}_{2}
\end{aligned}
$$

Equations (1) and (2) represent the autocatalytic deposition of nickel and nickel boride, and equation (3) is the spontaneous decomposition of borohydride ions which always takes place in the course of electroless nickel deposition. Thus, the molar ratio of evolved hydrogen gas to the deposited nickel, expressed as $\mathrm{H}_{2} / \mathrm{Ni}$, and the deposition rate of nickel were measured as a function of a concentration of the bath components. Boron content in the nickel deposits was less than 5 weight percent, therefore, boron content was neglected in calculating the value of $\mathrm{H}_{2} / \mathrm{Ni}$. The results are shown as a function of the monoethanolamine in the bath in Fig. 1-A. The deposition rate of nickel was found to be very small in the absence of MEA, but increased linearly with the addition

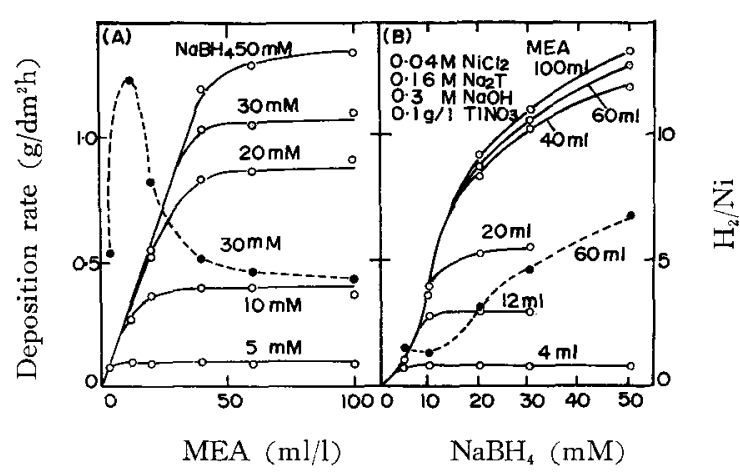

Fig. 1 Changes in deposition rate of nickel and ratio of $\mathrm{H}_{2} / \mathrm{Ni}$ with the concentration of MEA and/or $\mathrm{NaBH}_{4}$

of MEA up to a limiting value which was mainly controlled by the concentration of $\mathrm{NaBH}_{4}$. The dotted lines in Fig. 1 indicate the molar ratio of $\mathrm{H}_{2} / \mathrm{Ni}$. The value of $\mathrm{H}_{2} / \mathrm{Ni}$ is a good measure for the stability of the bath and also for the utility of the reducing agent. The value of $\mathrm{H}_{2} / \mathrm{Ni}$ had a maximum at $12 \mathrm{ml} / \mathrm{l}$ of $\mathrm{MEA}$ in the presence of $30 \mathrm{mM} \mathrm{NaBH}$ and decreased with increasing concentration of MEA. In Fig. $1-B$, the deposition rate of nickel is plotted against the concentration of sodium borohydride in the bath. The rate of nickel deposition increased rapidly with increasing concentration of $\mathrm{NaBH}_{4}$ up to $20 \mathrm{mM}$; beyond this point the deposition rate became to show an asymptotic increase or to be substantially constant depending on the concentration of MEA. At low borohydride concentrations, the deposition rate of nickel was mainly determined by a given borohydride concentration, regardless of the other components in the bath. The oxidation rate of $\mathrm{BH}_{4}^{-}$, which was practically controlled by its diffusion under these conditions, seems to be a main factor in determing the deposition rate of nickel. A high concentration of $\mathrm{NaBH}_{4}$ is unfavorable in operating the bath, because of a large value of the $\mathrm{H}_{2} / \mathrm{Ni}$. When the concentration of $\mathrm{NaBH}_{4}$ was larger than $30 \mathrm{mM}$, spontaneous decomposition of the bath took place at the specific concentration of MEA (12 and $20 \mathrm{ml} / \mathrm{l})$. The dependence of the deposition rate of nickel (solid line) and $\mathrm{H}_{2} / \mathrm{Ni}$ ratio (dotted line) upon the concentration of $\mathrm{Na}_{2} \mathrm{~T}$ and $\mathrm{NaOH}$ was shown in Fig. 2 as a function of the concentration of $\mathrm{NaBH}_{4}$. The deposition 


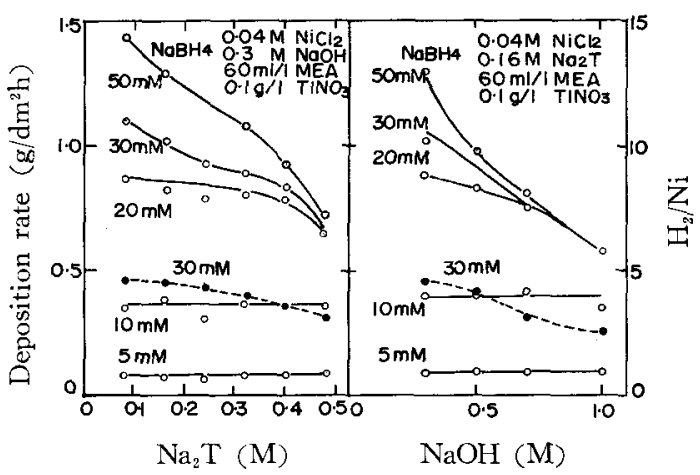

Fig. 2 Changes in deposition rate of nickel and ratio of $\mathrm{H}_{2} / \mathrm{Ni}$ with the concentration of $\mathrm{Na}_{2} \mathrm{~T}$ and/or $\mathrm{NaOH}$

rate of nickel and the $\mathrm{H}_{2} / \mathrm{Ni}$ ratio were found to decrease with increasing concentration of $\mathrm{Na}_{2} \mathrm{~T}$ or $\mathrm{NaOH}$ at high concentrations of borohydride. On the other hand, the deposition rate was independent of the concentrations of $\mathrm{Na}_{2} \mathrm{~T}$ or $\mathrm{NaOH}$ to give a constant value at low concentration of borohydride. It should be noted that in spite of the presence of the ligands, the solution was unstable as manifested by the spontanious decomposition of the bath. Thallous nitrate was introduced into the solution to prevent the decomposition of the nickel plating bath. Effects of $\mathrm{TINO}_{3}$ on the deposition rate of nickel and on the $\mathrm{H}_{2} / \mathrm{Ni}$ ratio are shown in

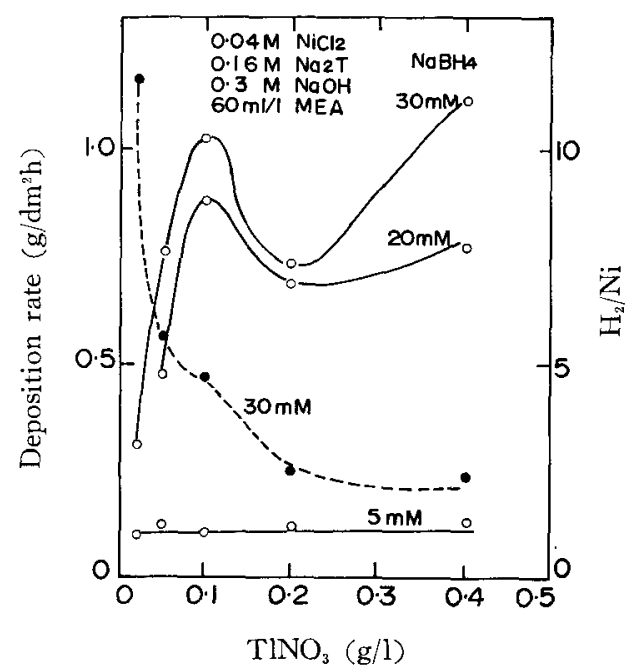

Fig. 3 Changes in deposition rate of nickel and ratio of $\mathrm{H}_{2} / \mathrm{Ni}$ with the concentration of $\mathrm{TlNO}_{3}$
Fig. 3. The ratio of $\mathrm{H}_{2} / \mathrm{Ni}$ decreased with increasing concentration of $\mathrm{TINO}_{3}$, and the bath became stable. On the other hand, the deposition rate of nickel had the maximum and minimum values at 0.1 and $0.2 \mathrm{~g} / 1 \quad \mathrm{TINO}_{3}$, respectively.

\subsection{Absorption spectra}

The deposition rate of nickel and the value of $\mathrm{H}_{2} / \mathrm{Ni}$ changed with the concentration of constituents in the bath as shown in the previous section. In order to explain the correlation between the structral changes of nickel complex in the bath and the deposition rate of nickel, spectrophotochemical studies of the bath were undertaken. Changes in spectra of a nickel tartrate solution at a high $\mathrm{pH}$ showed two absorption peaks and one shoulder in the region under investigation as shown in Fig. 4. The first

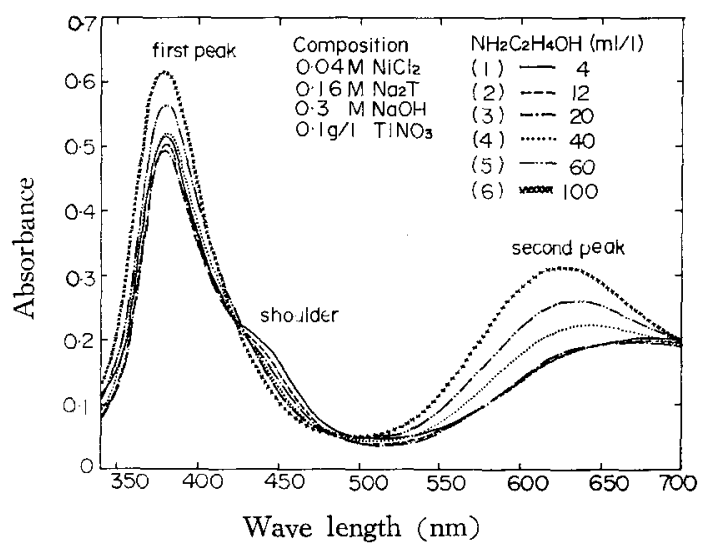

Fig. 4 Effect of MEA concentration on the spectra of nickel complexes

peak was about 2.5 times more intense than that of the second one. When MEA was added to the solution, both peaks shifted toward shorter wave length and became more intense than those for the nickel tartrate solution. In an alkaline solution, the tartrate ion has been found to coordinate to the nickel ion through the two carboxyl groups and one oxygen in $\mathrm{OH}$ as suggested by Bobtelsky ${ }^{8}$. It can be considered that the shoulder at about $450 \mathrm{~nm}$ is the characteristic feature of such a terdentate nickel tartrate complex. The shoulder was found to decrease with increasing concentration of MEA. Spectrophotometric investigations of a series of mixed complex formation were performed by Watters et $a l .{ }^{9) \sim 11}$. They found evidence for the forma- 
tion of a mixed complex using Job's method of continuous variations. The enhancement of the absorption due to the mixed complexes formed by nickel ion with both MEA and tartrate ion was confirmed in this investigation by using the same method adopted by Watters et al., but the composition of the mixed complex could not be determined on account of the following reasons. Tartrate ion in alkaline solution acts as terdentate or bidentate ligand under a given condition and the situation is further complicated by the presence of several mixed complexes in the solutions. A series of absorption curves obtained as a function of concentrations of $\mathrm{Na}_{2} \mathrm{~T}$ or $\mathrm{NaOH}$ are shown in Figs. 5 and 6 . The two peaks shifted toward longer wave length and became less intense with increasing concentrations of $\mathrm{Na}_{2} \mathrm{~T}$ or $\mathrm{NaOH}$; on the other hand,

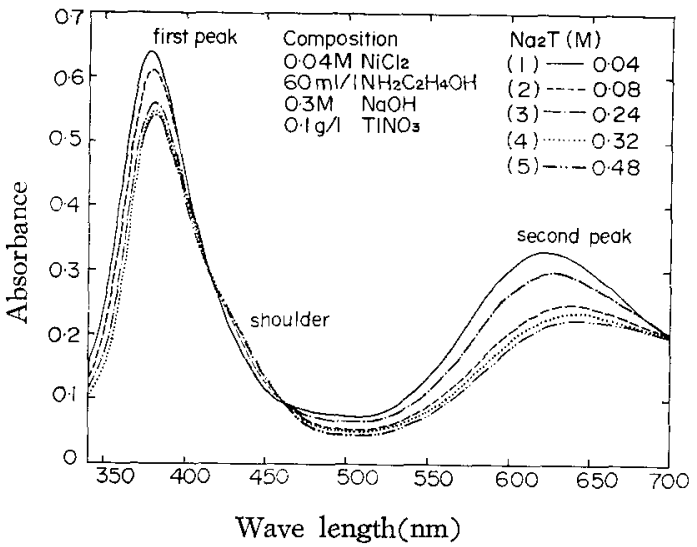

Fig. 5 Effect of $\mathrm{Na}_{2} \mathrm{~T}$ concentration on the spectra of nickel complexes

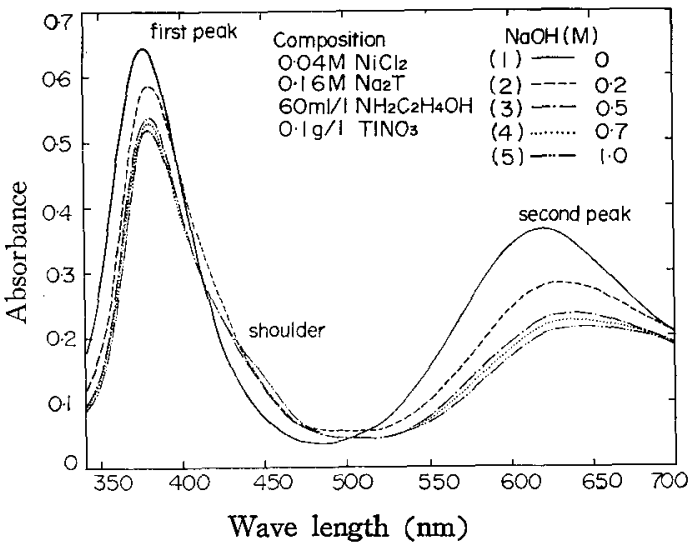

Fig. 6 Effect of $\mathrm{NaOH}$ concentration on the spectra of nickel complexes the shoulder became to be clear. It is concluded that several mixed complexes are formed by the addition of MEA to the alkaline solution containing nickel tartrate complex and that the concentration of the mixed complexes are altered by the concentration of MEA, $\mathrm{Na}_{2} \mathrm{~T}$ and $\mathrm{NaOH}$.

\subsection{Current-potential curves}

The process of nickel deposition in the electroless plating bath consists of two partial reactions, namely, the reduction of nickel ion to nickel metal (cathodic reaction) and the oxidation of borohydride ion to boric acid (anodic reaction). The effect of the MEA concentration on the characteristics of cathodic polarization curves in the electroless nickel plating bath is shown in Fig. $\%$. Since the

Potential ( $\mathrm{V}$ ws. $\mathrm{Hg} / \mathrm{HgO}$ )

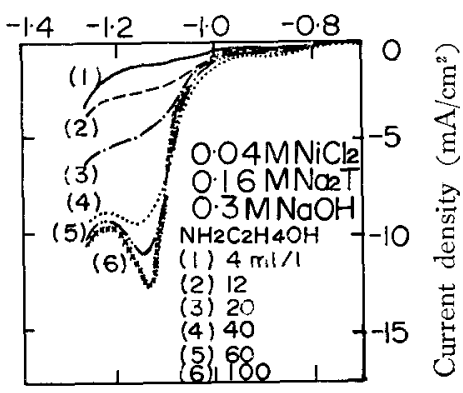

Fig. 7 Changes in cathodic polarization curves with the concentration of MEA

nickel tartrate complex is an electroinactive species as shown in the previous paper ${ }^{67}$ the reduction wave of nickel can not be observed before hydrogen evolution. However, when MEA was added to the nickel tartrate solution, two waves corresponding to the reduction of nickel were observed. The first and the second waves appeared at about $-0.8 \mathrm{~V}$ and $-1.1 \mathrm{~V}$ (vs. $\mathrm{Hg} /$ $\mathrm{HgO}$ ), respectively. The second wave depended strongly on the MEA concentration, but the first one was virtually constant independent of the MEA concentration. The two peaks were found to be diffusion-controlled as proved by the fact that a linear dependence of the peak current on the square-root of the potential sweep rate obtained in the range of about $4 \mathrm{mV} / \mathrm{s}$ to 200 $\mathrm{mV} / \mathrm{s}$. It is believed that these two waves are probably due to the reduction of new species of nickel complexes formed by an addition of 
MEA. The increase in the deposition rate of nickel with the addition of MEA corresponds to the increase of the second wave. When the concentrations of $\mathrm{Na}_{2} \mathrm{~T}$ or $\mathrm{NaOH}$ increased, the reduction current of nickel decreased and the polarization curves were slightly shifted to the more negative potential as shown in Fig. 8.

\section{Potential ( $\mathrm{V}$ vs. $\mathrm{Hg} / \mathrm{HgO}$ )}

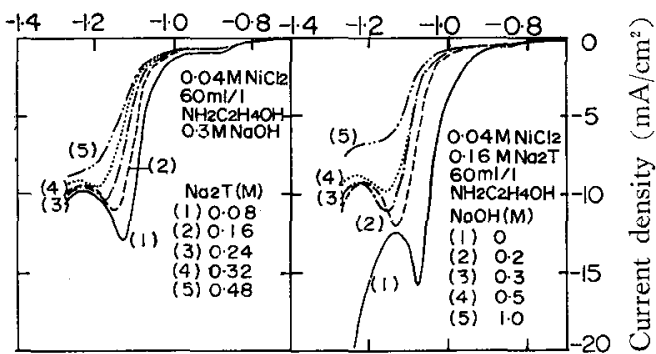

Fig. 8 Changes in cathodic polarization curves with the concentration of $\mathrm{Na}_{2} \mathrm{~T}$ and/or $\mathrm{NaOH}$

This fact could be explained by the increase in the conentration of electroinactive nickel tartrate complex. In this case, the deposition rate of nickel may approximately correlate to the magnitude of the second wave. Changes in the cathodic polarization curves by the addition of thallous nitrate in the electroless nickel plating bath are shown in Fig. 9. The magnitude of the first wave

$$
\text { Potential ( } \mathrm{V} \text { is. } \mathrm{Hg} / \mathrm{HgO} \text { ) }
$$

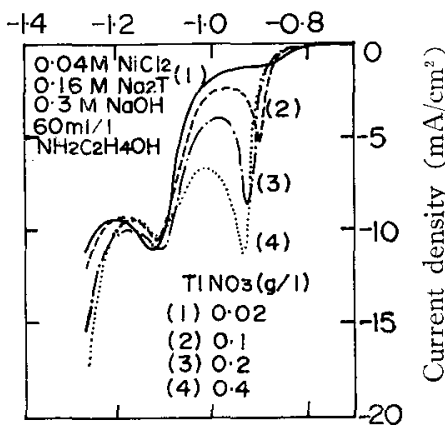

Fig. 9 Changes in cathodic polarization curves with the concentration of $\mathrm{TiNO}_{3}$

strongly increased and the reduction potential shifted toward the more negative potential with an increase of the concentration of $\mathrm{TlNO}_{3}$, but the second wave did not change and was virtually constant. Under the first peak, the reduction of thallous ion may occur, but the peak current was found to be about 50 times larger than that calculated by equation (1) with an assumption of the diffusion controlled reaction of thallous ion.

$$
I_{p}=347.8 n^{3 / 2} A C D^{1 / 2} V^{1 / 2}
$$

In the absence of nickel ion in the bath, the peak current became smaller and the magnitude of the current was in fair agreement with the value calculated from eq. (1), and the peak current appeared at the more positive potential. Therefore, the large peak current observed at about $-0.9 \mathrm{~V}$ might be attributable to the $\mathrm{co}^{-}$ deposition of the nickel and thallium metals. Changes in the anodic polarization curves for the oxidation of borohydride ion by the addition of MEA and $\mathrm{TlNO}_{3}$ to the alkaline tartrate solution are shown in Fig. 10. The oxidation

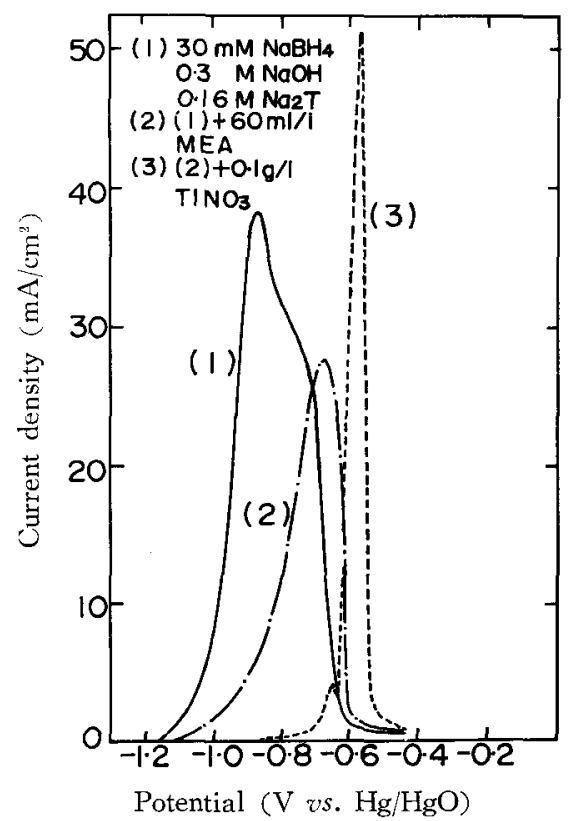

Fig. 10 Changes in anodic polarization curves with the composition of the electrolyte

wave of sodium borohydride in the alkaline tartrate solution (curve 1) appeared in potential range of about $-1.2 \mathrm{~V}$ to $-0.6 \mathrm{~V}$. The oxidation wave of sodium borohydride was partially inhibited by the addition of MEA owing to the weak adsorption of MEA to the nickel electrode surface and the polarization curve (curve 2) 
was found to shift to the more positive potential. An addition of $\mathrm{TINO}_{3}$ to this electrolyte, the oxidation of borohydride ion was completely inhibited (curve 3) and the anodic wave did not appear before the dissolution peak of thallium metal, $i . e$, in the potential range below about $-0.65 \mathrm{~V}$. It is believed that all or a part of the hydrogens in $\mathrm{BH}_{4}{ }^{-}$may be ionized on a suitable catalytic surface of the electrode in the course of the anodic oxidation. The oxidation process of borohydride ion may be influenced by the catalytic nature of the electrode surface. As thallium metal has no catalytic activity for the ionization of hydrogen as indicated by the high hydrogen overvoltage, therefore, the oxidation of borohydride ion may be, influenced by the non-catalytic thallium co-deposited in nickel. In this plating system, the electrode will not be completely covered with thallium metal owing to the co-deposition of nickel and thallium, therefore, autocatalytic deposition of nickel seems to occur continuously.

\section{Conclusions}

The deposition rate of nickel in an alkaline electroless nickel tartrate bath increased by the addition of MEA, but decreased with increasing concentration of $\mathrm{Na}_{2} \mathrm{~T}$ or $\mathrm{NaOH}$. Changes in the deposition rate of nickel in the bath can be interpreted by the analysis of the partial cathodic and anodic poarization curves on the basis of the mixed potential theory. The increased deposition rate of nickel by the addition of MEA may be interpreted in terms of the mixed complexes formed by nickel ion with both MEA and tartrate ions as suggested from the absorption spectral data and cathodic polarization curves. On the other hand, the decrease in the deposition rate of nickel with increasing concentration of tartrate or hydroxyl ion can also be interpreted in terms of the increase in concentration of the electroinactive nickel tartrate complex. At a low concentration of sodium borohydride the deposition rate of nickel was determined by the diffusion of $\mathrm{BH}_{4}{ }^{-}$, therefore, the rate of plating were almost constant regardless of the other components in the bath. Thallous ion introduced in the bath as a stabilizer adsorbed on the electrode surface and co-deposited with nickel, therefore, the molar ratio of $\mathrm{H}_{2} / \mathrm{Ni}$ decreased owing to the high hydrogen overvoltage of thallium. The recommended compositions of the electroless nickel plating bath in this investigation were as follows : $0.04 \mathrm{M} \mathrm{NiCl}_{2}, 0.16 \mathrm{M} \mathrm{Na}_{2} \mathrm{~T}, 40-60 \mathrm{ml} / \mathrm{l}$ MEA, $0.3-0.5 \mathrm{M} \mathrm{NaOH}$ and $0.1 \mathrm{~g} / 1 \mathrm{TINO}_{3}$.

$<$ E 496> (Received Mar. 14, 1977)

\section{References :}

1) C.H. deMinjer and A. Brenner, Flating 44, 1297 (1957).

2) K.A. Holbrook and P.J. Twist, ibid. 56, 523 (1969).

3) G.S. Alberts, R.H. Wright and C.C. Parker, J. Electrochem. Soc. 113, 687 (1966).

4) M. Matsuoka and T. Hayashi, Denki Kagaku 42, 424 (1974).

5) M. Matsuoka and T. Hayashi, ibid. 43, 399, 649 (1975).

6) M. Matsuoka and T. Hayashi, ibid. 41, 211 (1973).

7) H. Narcus, Plating 54, 380 (1967).

8) M. Bobtelsky and J. Jordan, J. Amer. Chem. Soc. 67, 1824 (1945).

9) J.I. Watters, J. Mason and A. Aaron, ibid. 75, 5212 (1953).

10) R. DeWitt and J.I. Watters, ibid. 76, 3810 (1954).

11) J.I. Watters and R. DeWitt, ibid. 82, 1333 (1960). 